\title{
Distribution characteristics of seepage field and prediction of water inflow before and after tunnel construction
}

\author{
CAO Ruilang ${ }^{1,2, a}$, PANG Shijie ${ }^{3}$ and HUANG Chang ${ }^{1,2}$, CHEN Chen ${ }^{1}$ \\ ${ }^{1}$ China Institute of Water Resources and Hydropower Research, Beijing, China \\ ${ }^{2}$ Fujian Research Center for Tunneling and Urban Underground Space Engineering, Huaqiao University, Xiamen, China \\ ${ }^{3}$ Yankuang Group, Shaanxi Future Energy Chemical Corp, Yulin, China
}

\begin{abstract}
In the construction of a deep tunnel with rich water and soft rock, accurate evaluations of the distribution characteristics of seepage field and water inflow are important bases for predicting the stability of tunnel surrounding rock and the disturbance state of groundwater environment. This paper used the Flac3D finite difference software seepage module, based on field geological borehole, measured seepage parameters and groundwater level. A three-dimensional numerical model of geological seepage in engineering area was established. The distribution characteristics of groundwater seepage field, the variation law of seepage field before and after tunnel excavation, and the water inflow during construction period were studied. As the tunnel was excavated, the excavated surface became a drainage channel, the isoline of groundwater pressure was changed into parallel non-parallel curve set by the parallel line of the initial seepage field. The nearer the tunnel centre was, the more obvious the variation tendency of groundwater pressure was. Grouting measures were very effective for tunnel water gushing, which not only reduced water inflow, but also effectively reduced the external water pressure of lining. It was infeasible to plug water when blocking the water without grouting and only adjusting the permeability of the lining.
\end{abstract}

\section{Introduction}

For tunnel excavation in water rich soft rock strata, the engineering geological conditions are often very complex. For example, karst and fractured zones can be found in bad geological conditions. In these conditions, groundwater problems, especially high hydrostatic pressure, are one of the important problems that builders cannot avoid ${ }^{[1]}$. The evaluation of tunnel groundwater environment and the prediction of tunnel water inflow methods mainly include the analytic calculation method and numerical method ${ }^{[2,3]}$. The analytical method has strict demands on model boundaries and formation regularity, compared with the analytical method. The numerical simulation can deal with the more complicated seepage boundary, and the application range is wider, furthermore the results are more in line with the actual engineering ${ }^{[4]}$. Tunnel is a typical underground structure so the groundwater is one of engineering challenges in the whole process of both construction and application $^{[5]}$. The permeability of rock is usually particularly low, but for rock mass, because of the complex rock pores, fractures, structural planes and tectonic zone will increase the permeability of rock causing great pore water pressure in the rock mass which results in several problems for geologic engineer to solve $^{[6]}$
This paper used the Flac3D finite difference software seepage module ${ }^{[7]}$, based on field geological borehole, measured seepage parameters and groundwater level. Numerical simulation is used to simulate and analyse the changes of water pressure, water inflow, stress, displacement and water flow in the process of excavation, to verify the correctness of the theoretical analysis results, and to guide the construction of the actual project $^{[8,9]}$. The research results will put forward new ideas for groundwater treatment technology and construction of underground engineering such as high water pressure tunnel, mine tunnel and urban subway under complex geological conditions in the future. It provides practical theoretical basis for engineering practice, and promotes the basic theory and construction practice of tunnel grouting technology ${ }^{[10]}$.

The distribution characteristics of seepage field, the variation law of seepage field before and after tunnel excavation and the water inflow during construction period were studied in this article. The simulation results have guiding significances for the development of fissures and the design of waterproof and drainage tunnels in water rich formations.

\section{Geological and hydrological condi- tions of tunnel site}

The hydrogeological conditions of tunnel site are shown in figure 1. Under the influence of the structure, the rock

\footnotetext{
${ }^{*}$ Corresponding author: ${ }^{\text {a }}$ CAO Ruilang: finite@yeah.net 
fissure joints in the tunnel area were relatively developed. Because of the effect of groundwater seepage on the joint surface, eight karst caves had been found by geological survey, two of them were karst caves with water. The measured flow rate of karst cave with water was $320-775 \mathrm{~m}^{3} / \mathrm{d}$, which was greatly affected by atmospheric precipitation. Many factors had created favourable conditions for occurrence and migration of groundwater.

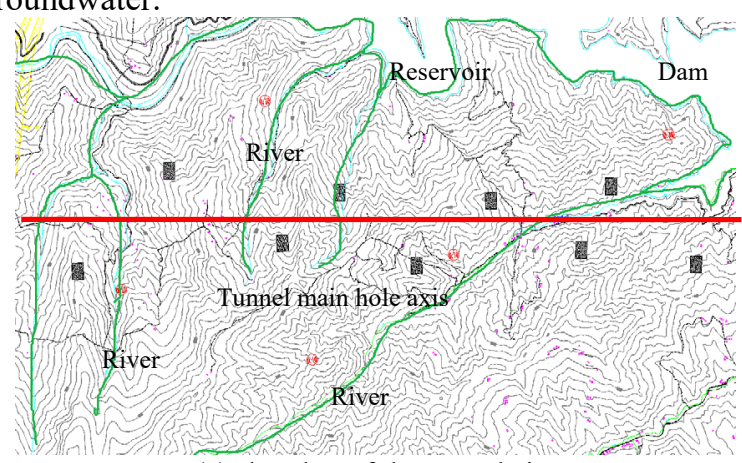

(a)The plan of the tunnel site

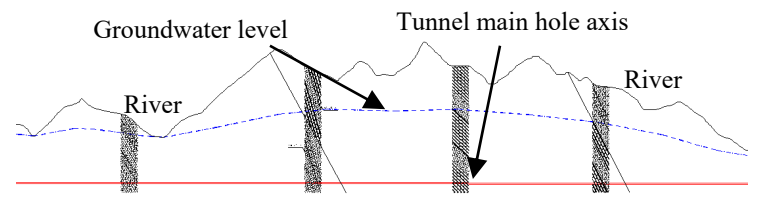

(b) The vertical view of the tunnel site

Figure 1. Hydrogeological condition of tunnel site.

\section{Numerical modelling and calculation scheme}

\subsection{Numerical calculation model and parameters}

The three-dimensional seepage model of tunnel site is shown in figure 2, and the fl_iso model in Flac3D was used in the seepage calculation model. In the process of tunnel construction, the external seepage boundary conditions of the model were the boundary of the river and the boundary of the watershed.

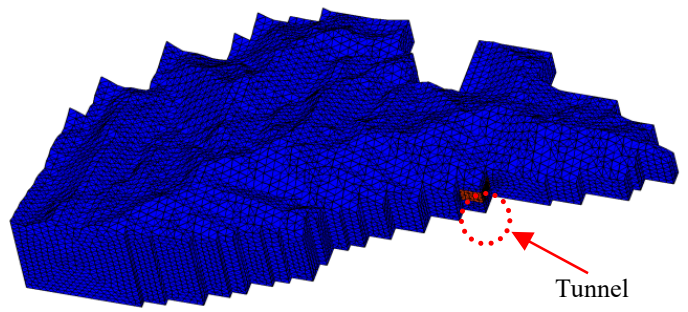

(a) 3D model diagram
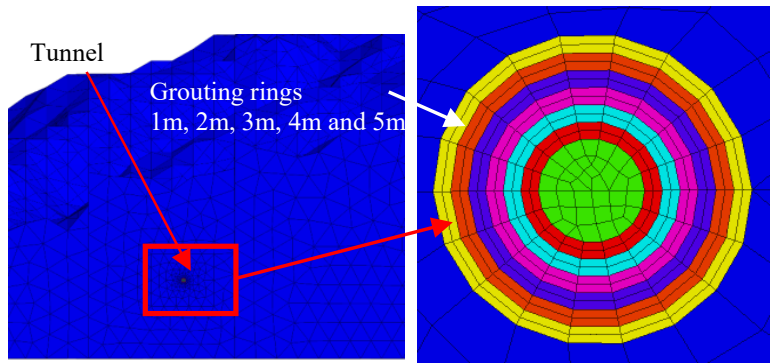

(b) Local model diagram

Figure 2. Three-dimensional seepage model of tunnel site.
The surface of the formation was the zero-free surface of water pressure. The model water pressure gradient was interpolated according to the measured water pressure of geological borehole, and the water pressure in the model was increased from top to bottom. When the tunnel was excavated, the ground water pressure of the excavated surface was set to zero to simulate the characteristics of the seepage channel after tunnel excavated. According to the stratigraphic lithology and geological structure characteristic of the tunnel through the area, the groundwater of the measured area is the pore water of the Quaternary loose rock, the carbonate rock type karst water, and the bedrock fissure water.

The physical mechanics and seepage parameters of surrounding rock were based on the measured values of geological boreholes. The specific parameters are given in table 1.

Table 1. Physico mechanical and seepage parameters of tunnel surrounding rock

\begin{tabular}{cccc}
\hline $\begin{array}{c}\text { Surrounding rock } \\
\text { classification }\end{array}$ & III & IV & V \\
\hline Density $r\left(\mathrm{kN} / \mathrm{m}^{3}\right)$ & 24.6 & 22.5 & 21.0 \\
Elastic modulus $E(\mathrm{GPa})$ & 7.1 & 3.2 & 1.1 \\
Poisson's ratio $v$ & 0.28 & 0.3 & 0.35 \\
$\begin{array}{c}\text { Permeability coefficient } \\
(\mathrm{m} / \mathrm{s})\end{array}$ & $1.2 \times 10^{-5}$ & $6.5 \times 10^{-5}$ & $1.5 \times 10^{-4}$ \\
\hline
\end{tabular}

\subsection{Calculation scheme}

In order to study the distribution characteristics of seepage field and prediction of water inflow before and after construction in water rich stratum under various working conditions. The numerical scheme included:

- Initial seepage field calculation;

- Excavation of tunnel without lining and grouting;

- Tunnel excavation with lining and without grouting;

- Excavation plan of grouting depth with $1 \mathrm{~m}, 2 \mathrm{~m}, 3 \mathrm{~m}$, $4 \mathrm{~m}$, and $5 \mathrm{~m}$;

- Tunnel excavation scheme under different ratio of permeability of lining.

\section{Distribution law of seepage field}

\subsection{Initial seepage field}

A three-dimensional seepage analysis model was established, and the initial seepage field distribution of tunnel surrounding rock was calculated before construction. The initial seepage field profile of the three dimensional model of tunnel site is shown in figure 3 . The calculated groundwater level was basically consistent with the measured water level of geological borehole. The typical seepage field distribution of different types of surrounding rock (III, IV, and V) is shown in figure 4.

Under the undisturbed condition, the seepage field distribution of the surrounding rock basically conformed to the hydrostatic stress field. The maximum velocity of 
rock mass was $4.45 \times 10^{-6} \mathrm{~m} / \mathrm{s}$, the rock flow velocity increases with the permeability coefficient of rock mass.

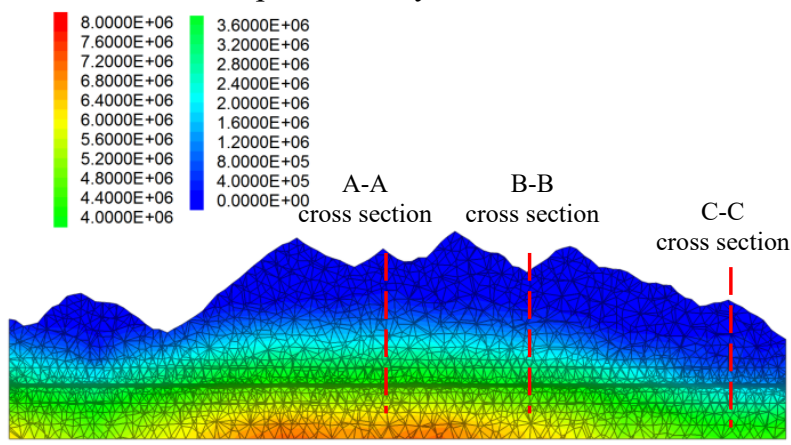

Figure 3. Profile of initial seepage field in $3 \mathrm{D}$ model of tunnel site $(\mathrm{Pa})$.

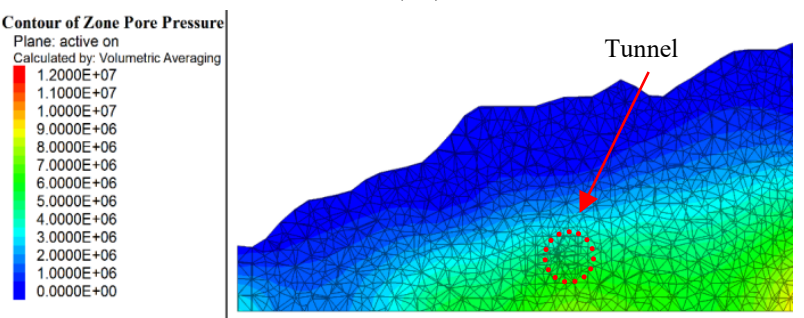

(a) A-A cross section (III type surrounding rock)

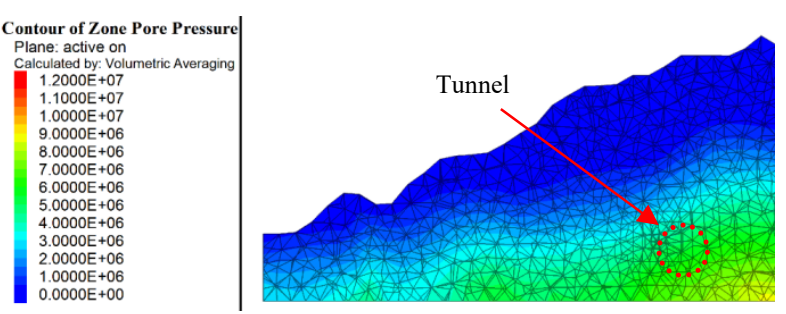

(b) B-B cross section (IV type surrounding rock)

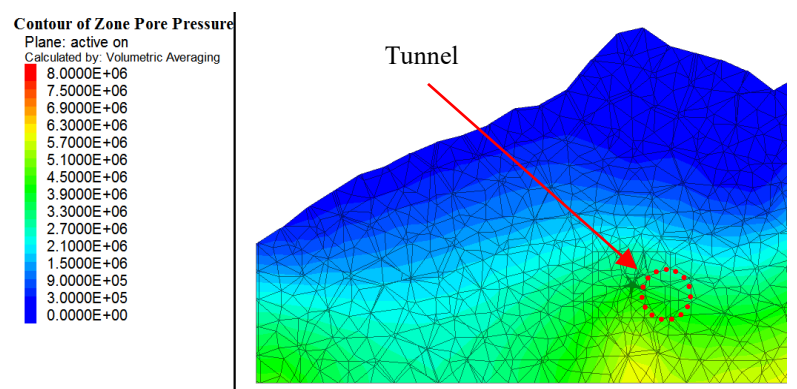

Figure 4. Seepage field distribution of different types of surrounding rock $(\mathrm{Pa})$

\subsection{Variation law of seepage field before and after tunnel excavation}

The water pressure diagram of the seepage field without grouting excavation (see figure 5) can be seen, as the tunnel was excavated, the excavated surface became a drainage channel, the isoline of groundwater pressure was changed into non-parallel curve set by the parallel line of the initial seepage field. The excavation had little influence on the seepage field below the tunnel, and had great influence on the seepage field above the tunnel. According to the distribution pattern of typical section water pressure (see figure 4), variation trend of groundwater pressure got more obvious when it got nearer to the tunnel centre. The influence of tunnel excavation on the initial seepage field of surrounding rock was less than $150 \mathrm{~m}$, about 20 times the diameters of tunnel.

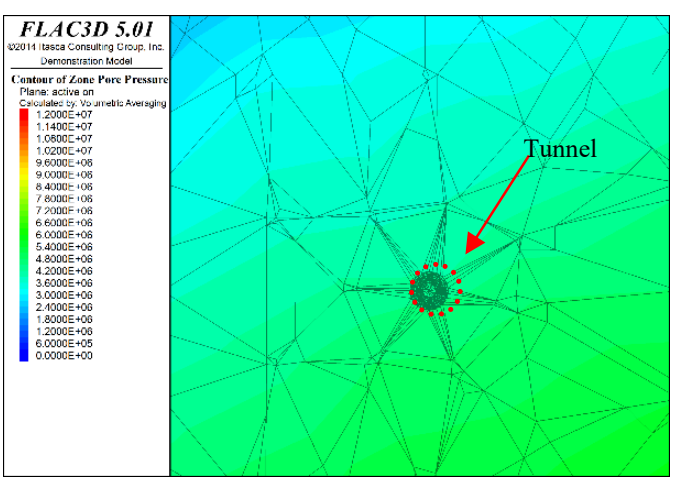

(a) Before tunnel excavation

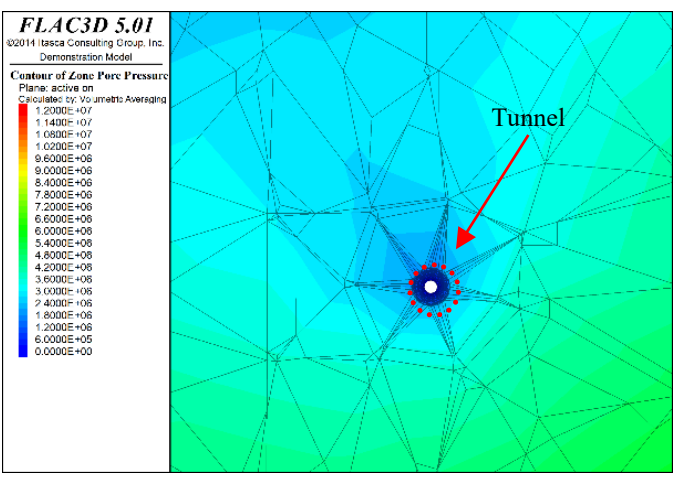

(b) After tunnel excavation

Figure 5. Seepage field variation of surrounding rock before and after tunnel excavation $(\mathrm{Pa})$.

\subsection{Analysis of water inflow in tunnel under different calculation schemes}

The water inflow of tunnel under different calculation schemes is shown in Figure 6, and the pore water pressure distribution at different depths in the vault is shown in Table 2. The calculation results show that grouting measures are effective for tunnel water gushing, which can not only reduce water inflow, but also effectively reduce the external water pressure of lining. It was beneficial to the stability of retaining structure. The outer water pressure of the lining was about $0.7 \mathrm{MPa}$ without grouting. With the increase of grouting depth, the water pressure of the lining decreased obviously. When the grouting depth were $2 \mathrm{~m}$ and $4 \mathrm{~m}$, the water pressure difference between the lining was about $20 \%$.

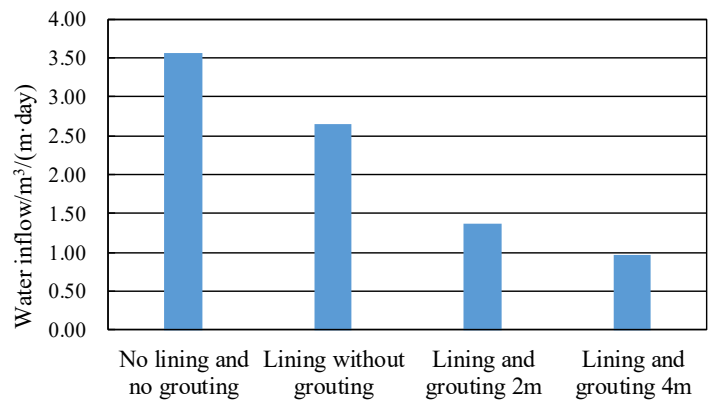

Figure 6. Water inflow of tunnel under different calculation schemes. 
Table 2. Calculation results of different anchor encircled

\begin{tabular}{|c|c|c|c|c|}
\hline \multirow[b]{2}{*}{$\begin{array}{l}\text { Depth } \\
\text { /m }\end{array}$} & \multicolumn{4}{|c|}{ Pore water pressure $/ \mathrm{MPa}$} \\
\hline & $\begin{array}{l}\text { No lining } \\
\text { and no } \\
\text { grouting }\end{array}$ & $\begin{array}{l}\text { Lining } \\
\text { without } \\
\text { grouting }\end{array}$ & $\begin{array}{l}\text { Lining and } \\
\text { grouting } \\
2 \mathrm{~m}\end{array}$ & $\begin{array}{l}\text { Lining and } \\
\text { grouting } \\
4 \mathrm{~m}\end{array}$ \\
\hline 0 & 0.051 & 0.600 & 0.412 & 0.369 \\
\hline 1.0 & 0.207 & 0.714 & 1.036 & 0.873 \\
\hline 2.0 & 0.323 & 0.777 & 1.035 & 1.130 \\
\hline 4.0 & 0.397 & 0.817 & 1.127 & 1.229 \\
\hline 6.0 & 0.480 & 0.853 & 1.106 & 1.244 \\
\hline 8.0 & 0.569 & 0.901 & 1.163 & 1.257 \\
\hline
\end{tabular}

The relation between the tunnel water inflow and the permeability of the grouting ring and lining is shown in Figure 7 . When the grouting ring thickness was constant, the water inflow of the tunnel decreased with the decrease of the permeability coefficient of the grouting ring. When the permeability of grouting ring dropped to a certain extent (for example, when the permeability coefficient of grouting ring was reduced to five present of the seepage coefficient of surrounding rock), the decrease effect of tunnel water inflow was not obvious. Therefore, there is an economic and reasonable interval to adjust the permeability coefficient of surrounding rock by grouting. In addition, if the water plugging scheme is not adopted at the same time, it is uneconomical to adjust the permeability of the lining to achieve the effect of water plugging. Even if the permeability coefficient of lining was reduced to a very low value $(1.25 \%$ of the seepage coefficient of surrounding rock), the water inflow couldn't be greatly reduced. Obviously, the combination of grouting water plugging and lining water plugging is more economical and reasonable.

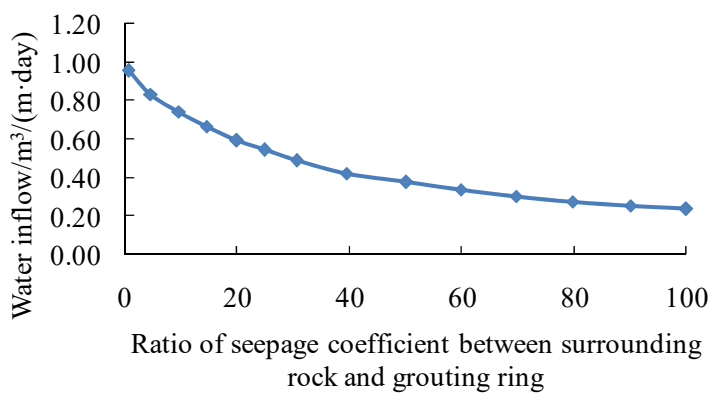

(a) Variation of permeability coefficient of grouting ring

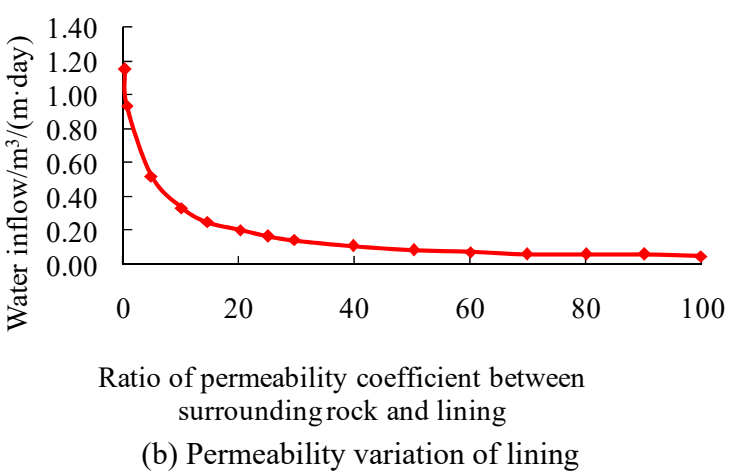

Figure 7. Relationship between water inflow of tunnel and permeability of grouting ring and lining.

\section{Conclusions}

As the tunnel was excavated, the excavated surface became a drainage channel, the isoline of groundwater pressure was changed into parallel non-parallel curve set by the parallel line of the initial seepage field. The nearer the tunnel centre was, the more obvious the variation tendency of groundwater pressure was. The influence area was about 20 times the tunnel diameters. Grouting measures were very effective for tunnel water gushing, which not only reduced water inflow, but also effectively reduced the external water pressure of lining. It was advantageous to support structure stability. It was infeasible to plug water when blocking the water without grouting and only adjusting the permeability of the lining.

\section{Acknowledgements}

This work is supported by the National key research and development project (No. 2016YFC0401801) and Fujian Research Centre for Tunnelling and Urban Underground Space Engineering (No. 17FTUE01).

\section{References}

1. Yingzi C. Numerical simulation and prediction on seepage field and water gushing of Da'ao tunnel zone.D. (2014).

2. Shuqing W. Prediction and disposal principle of high water flow in tunnel surrounding rock.D. (2013).

3. Pengfei L, Dingli Z, Ye Z. Study on prediction methods and its influence factors of water inflow into tunnels. Journal of Beijing Jiaotong University. J.34(4):11-15(2014).

4. Wang J, Zhu H, Ye W. Forward and inverse analyses of water flow into tunnels. Chinese Journal of Rock Mechanics \& Engineering.J.23(7):11501153(2004).

5. Farhadian H, Hassani A N, Katibeh H. Groundwater inflow assessment to Karaj Water Conveyance tunnel, northern Iran[J]. Ksce Journal of Civil Engineering, 2016:1-10. 
6. Linbin C, Tan C, Lei S, et al. Assessment of Water Inflow in Mountain Tunnel and Back Analysis for Tunneling Construction $[\mathrm{J}]$. Tunnel Construction, 2010.

7. Itasca Consulting Group, Inc. Fast Lagrange Analysis of continua in 3 dimensions. R. 2-6(2011).

8. Pinzani A. A practical approach for the evaluation of tunnel water inflow by means geostructural field survey[J]. Rendiconti Online Societa Geologica Italiana, 2012, 22:190-193.

9. Park K H, Owatsiriwong A, Lee J G. Analytical solution for steady-state groundwater inflow into a drained circular tunnel in a semi-infinite aquifer: A revisit[J]. Tunnelling \& Underground Space Technology, 2008, 23(2):206-209.

10. Zhao G, Chen Z, Zhou Y, et al. Review of numerical study on groundwater inflow forecasting in deep-buried tunnel construction[J]. Geotechnical Investigation \& Surveying, 2017. 